\title{
La poética artística como herramienta de acción política para la promoción del afecto: una acción poético-afectiva en territorios afectados de la Cuenca del Rio Doce
}

\author{
Vanessa Jesus
}

Universitàt Politècnica de València, vafloje@ bba.upv.es

\begin{abstract}
All people are powerful and have many powers. But many times in from of a catastrophe those powers are forgotten or lost. We believe in artistic practice as an element of affective restoration, a basic element of social transformation, mainly together with communities that find themselves in situations of crisis, vulnerability and invisibility, caused by wars, social inequality or environmental catastrophes.

Faced with the environmental catastrophe of the Rio Doce, we share the practical experience of artistic creation in some of the communities of the Doce River basin, between the provinces of Espirito Santo and Minas Gerais, in Brazil. An artistic practice that has the intention of provokingempathy through the listening of the affective memories with the Rio with the idea of an affective regeneration, that allows a possibility of the person to feel part of the world again.
\end{abstract}

Keywords: Keywords: body, territory, affection, memory, regeneration

\begin{abstract}
Resumen
Todas las personas son potentes y tienen muchas potencias. Pero muchas veces al devenir una catástrofe esas potencias son olvidadas o perdidas. Creemos en la práctica artística como elemento de restauración afectiva, elemento base de transformación social, principalmente junto a comunidades que se encuentran en situaciones de crisis, vulnerabilidad e invisibilidad, ocasionadas tanto por guerras, desigualdad social o catástrofes ambientales.

Frente a la catástrofe ambiental del Rio Doce, compartimos la experiencia práctica de la creación artística en algunas de las comunidades de la cuenca del río, entre las provincias de Espirito Santo y Minas Gerais, en Brasil. Una práctica artística que tiene la intención de provocar la empatía a través de la escucha de las memorias afectivas con el Rio Doce; con la idea de una regeneración afectiva, que permita la posibilidad a las personas de se sentirse parte del mundo otra vez.
\end{abstract}

Palabras clave: cuerpo, territorio, afecto, memoria, regeneración 
La poética artística como herramienta de acción política para la promoción del afecto: Una acción poético-afectiva en territorios afectados de la Cuenca del Rio Doce

\section{Introducción}

Estamos en el 2019, para el día 5 noviembre se cumplirán 4 años desde el desastre que cambió la vida y la historia de muchas personas y comunidades.

Después de una catástrofe, bien sea por desastre natural, humano o guerra, se puede reconstruir físicamente una ciudad, en caso de que haya sido destruida. ¿Pero cómo se reconstruyen las vidas humanas? No hablo de las vidas humanas que se perdieron sino de las vidas humanas que se quedaron, físicamente, pues muchas veces, dependiendo de la intensidad de la catástrofe, sólo se queda el cuerpo.

¿Cómo se reconstruye la vida después de una catástrofe? ¿Quién te ayuda?

¿Con qué y quién se puede contar?

Este proyecto nace de mi mayor deseo: que el Arte pueda ser un medio de apoyo para unir a las personas después de catástrofes, no en un sentido terapéutico directamente, pero sí usar el factor de la creación artística como herramienta para pensar juntos una nueva opción, una creación de lo que queremos. Pues creo que sólo podemos desarrollarnos con la cooperación, y nada mejor que la creación artística en cooperación para proporcionar ese estado. La creación artística no tiene reglas pre-establecidas, ella te lo da el impulso a pensar lo que quieres hacer y a sacar de ti tus potenciales. Potencializando la fuerza de los individuos y de los grupos.

Veo en la creación/ práctica artística un impulso y apoyo para el ser que ya no tiene más esperanza.

Planteo ese proyecto como continuación de la práctica que inicié con algunos habitantes de las comunidades afectadas por la catástrofe del rompimiento de un dique de contención de desechos de una empresa minera multinacional en Brasil. Ese desastre ambiental, no solo destruyó uno de los más importantes ríos de mi país, destruyó también ciudades enteras, familias, comunidades, alimentos, fuentes de ingresos financieros, turismo, fuente de agua, culturas, tradiciones, y, para mí, lo más grave que pude presenciar y vivir, fue la destrucción de la perspectiva de futuro de las personas. Pues una casa se reconstruye, pero ¿quién limpia el río?

¿Qué hacemos ahora? la primera pregunta que viene a la cabeza cuando te pasa algo de esta magnitud, como una perdida una catástrofe que cambia tu vida. Esa pregunta no viene con una respuesta fácil y muchas veces no hay a quién preguntarla. Ese proyecto se plantea, no con la idea de tener una respuesta, pero sí de crear un espacio y apoyo para pensar juntos una nueva posibilidad.

\section{Objetivos}

- Activar recuerdos personales y afectivos con el territorio antes de la tragedia.

- Crear momentos de encuentros afectivos/empáticos y relajados con las habitantes de las comunidades.

- Demostrar empatía a través de la escritura de cartas afectivas creadas, especialmente, a partir de los encuentros con las habitantes de las comunidades de la cuenca del Rio Doce.

- Promover las historias, memorias, luchas, necesidades y deseos de las poblaciones en los diversos ambientes a nivel nacional e internacional.

- Apoyar sus eventos, tradiciones y luchas

\section{Cuenca hidrográfica del Rio Doce}

La cuenca más importante del sureste de Brasil, cubre un área de $83.400 \mathrm{~km}^{2}$ donde 230 municipios utilizan su lecho como subsistencia. El 5 de noviembre de 2015, ocurrió el rompimiento de un dique de desechos de minería en el 
subdistrito de Bento Rodrigues, en la ciudad de Mariana, Minas Gerais, que dejó 11 muertos, 12 desaparecidos y millares de desamparados en el municipio y ocasionó una oleada de 62 millones de metros cúbicos de desechos de minería, que se lanzaron en el Rio Doce, recorriendo cientos de kilómetros hasta llegar a su desembocadura, en el litoral del Espirito Santo, una importante área de corales, provocando enormes daños a los ecosistemas de la cuenca del río Doce. Ha causado la suspensión del suministro de agua potable a cerca de 250 mil personas, como consecuencia de la cantidad de barro y de la presencia de metales como el arsénico, cadmio, plomo, cromo, níquel, cobre y mercurio por sobre el límite legalmente permitido.

Daños ocasionados por el rompimiento del dique: Destrucción de Bento Rodrigues; el aumento de la turbidez de las aguas del río Doce, con impactos en el abastecimiento de agua en ciudades de Minas Gerais y Espírito Santo, daños culturales a monumentos históricos del período colonial, así como a la fauna y la flora en la cuenca hidrográfica, incluyendo posible extinción de especies endémicas, y perjuicios a la actividad pesquera y el turismo en las localidades afectadas.

Áreas afectadas: Subdistrito de Bento Rodrigues, diversos municipios a orillas del Río Doce y Océano Atlántico. De los municipios afectados, fueran elegidos tres para trabajar, por su diversidad económica, estructural, ubicación geográfica y fauna. Que son: Regencia, Mariana y Governador Valadares.

Vila Regência (comunidad de pescadores - región donde el rio desemboca al Océano Atlántico)

Comunidad de habitantes descendentes de indios, caboclos y pescadores, sus principales atractivos de la villa son las olas propicias a la práctica de surf, la "Fiesta de Caboclo Bernardo", donde hay el encuentro de las bandas de congo del Espirito Santo, la tradicional "Fiesta de los Pescadores de Regencia" y la principal base del Proyecto TAMAR del estado. Actualmente el pueblo se encuentra en desamparo político y económicos con sus liderazgos debilitados. Los pescadores ya no pueden más pescar y el turismo ya casi no existe más, debido la contaminación de las aguas del Rio que llegó a las playas de la región.

Fig. 1 Antes

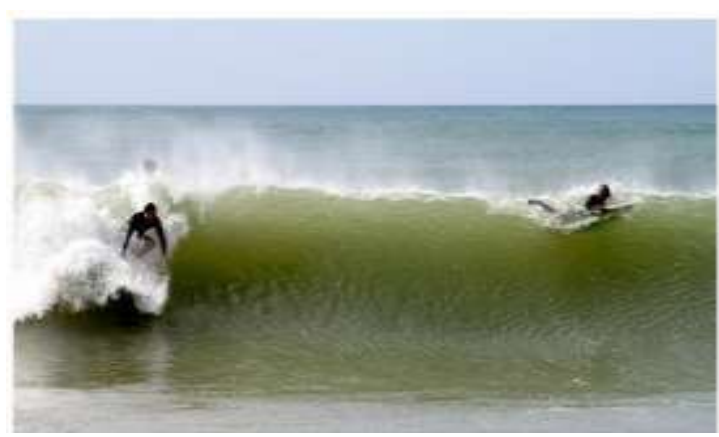

Fig 2. Después

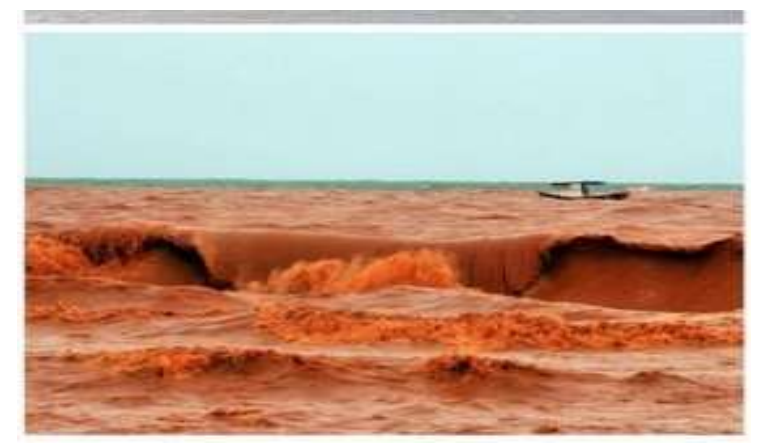

(Fotos: Bocana Surf Camp e Fernando Madeira)

Mariana (municipio a 35km donde se rompió el dique, región con mayor cuantidad de comunidades afectadas)

Tiene cerca de 58 mil habitantes, la economía local depende principalmente del turismo y la extracción de minerales. Es una de las ciudades que integran el Cuadrilátero Ferrífero, región responsable por el $60 \%$ de toda la producción nacional de mineral de hierro, donde opera Vale S.A., la segunda mayor empresa minera del mundo. Es la capital de la región donde está ubicado el subdistrito de Bento Rodrigues, que fue casi completamente inundado y destruido por la sequía de lodo que siguió tras el desastre en la represa. La ciudad posee un enorme patrimonio arquitectónico del bbarroco producido durante el Brasil Colonial. Recibe buena parte del flujo de turistas de Ouro Preto, debido a la pequeña distancia de 12 km.- región muy conocida y procurada por los carnavales. Las noticias de los medios nacionales e internacionales sirvieron para disminuir el turismo de la ciudad y cerrar la empresa que, para los residentes, generaba empleos y renta. 
La poética artística como herramienta de acción política para la promoción del afecto: Una acción poético-afectiva en territorios afectados de la Cuenca del Rio Doce

Fig.3 Bento Rodrigues Antes

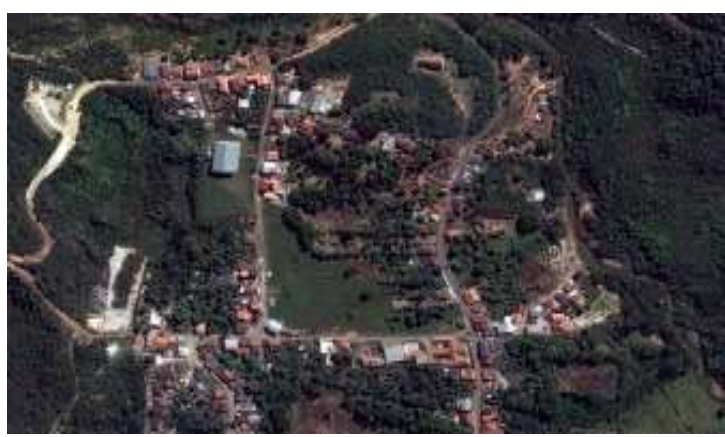

Fig.4 Bento Rodrigues Después

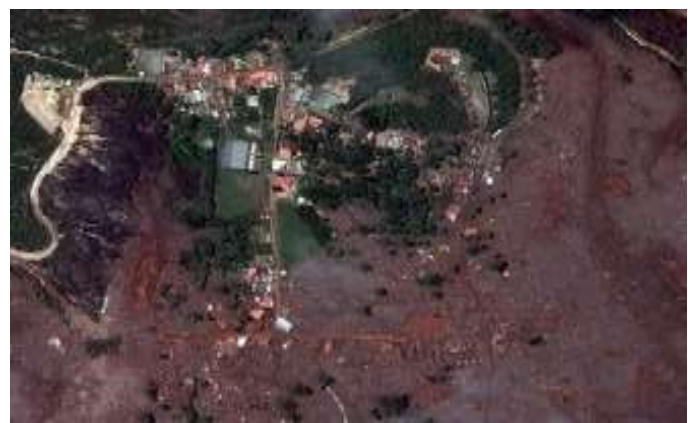

Satélite WordView2. Recuperado: https://www.em.com.br/app/noticia/gerais/2015/11/12/interna_gerais,707158/imagens-de-satelite-mostrambento-rodrigues-antes-e-depois-de-tragedia.shtml

Governador Valadares (mayor ciudad de la Cuenca Hidrográfica del Rio Doce con 278 mil habitantes- situada en el valle del río Doce)

Es un polo económico del Vale do rio Doce, se sitúa a orillas del Rio Doce. Conocido como "Princesinha do Vale" (Princesita del Valle) y "Capital do Vale do Rio Doce" (Capital del Valle de río Doce), por ser la ciudad principal bañada por este río, siendo este uno de sus principales atractivos turísticos. Una de las regiones más afectadas con el desastre, que dejó sus 278mil habitantes sin agua después que el lodo toxico llegó al Río Doce, que afecto la Usina de Baguari, principal responsable por el suministro de agua de la región.

Fig. 5 Usina de Baguari - Antes

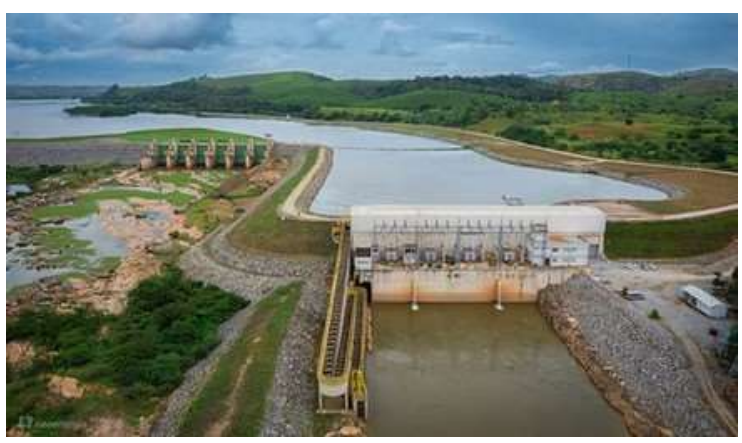

Foto: UHE Baguari / Divulgação
Fig. 5 Usina de Baguari - Después

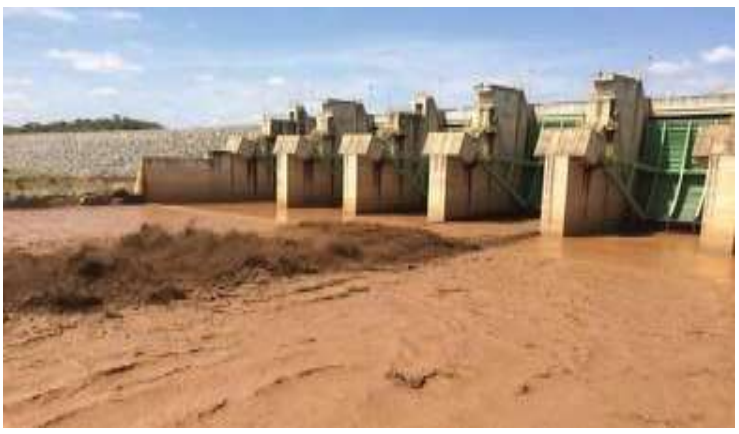


Fig. 7 Trayecto del Lodo Tóxico

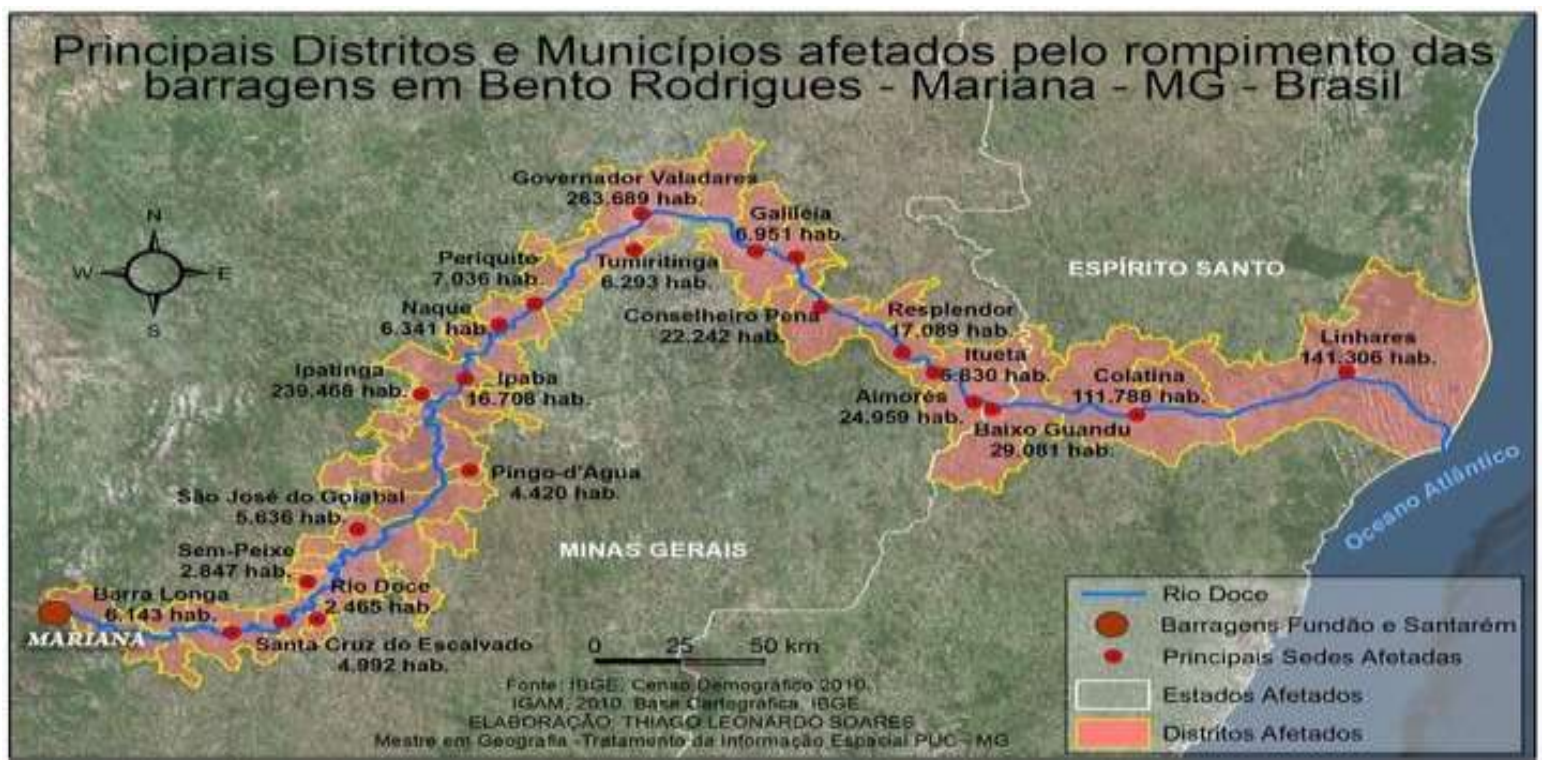

(Fonte: IBGE Censo Geográfico 2010)

Recuperado de:https://www.todamateria.com.br/desastre-de-mariana/

\section{La poética Artística como acción política}

Recorrimos el trayecto de los desechos, de Mariana hasta Regencia, 563km, del dique hasta el Mar. Vimos el encuentro del Rio Gualaxo con el Río Carmo en Barra Longa, y al encuentro del Río Carmo con el Río Doce, en la ciudad de Río Doce. En las siete comunidades afectadas que hemos visitado, conversamos con dieciséis personas, una persona simbolizando cada día del trayecto de los desechos hasta llegar a la playa. Las moradoras afectadas fueron elegidas a partir de relaciones de afecto pre- establecidas en el año de 2017, y por indicación de otras moradoras. A cada encuentro, fue desarrollada una escucha empática de sus memorias afectivas con el territorio y sus sueños personales y colectivos mientras yo los ayudaba con alguna tarea de la casa, del huerto, del patio o merendábamos.

Para ellas era muy importante que el formato del encuentro no fuera como una entrevista, y sí que hablásemos mientras hacían algo. Yo aproveche el formato de conversa performática para poder cuidar del tiempo del encuentro, y poder cuidar mínimamente de cada persona en el momento de ese encuentro, pues las personas elegidas fueran personas que tienen en su trayectoria la practica del cuidado, sea el con su familia, comunidad, profesionalmente o en general en sus vidas. Pues para ese proyecto es, e fue importante cuidar de las que cuidan. Poder cuidar y amparar afectiva mente cada persona como individuo para que ella pueda estar bien como colectivo.

A partir de los encuentros fueran creadas cartas- memorias afectivas con el registro del encuentro y de las memorias compartidas, las cartas están divididas en tres momentos: agradecimiento por compartir sus recuerdos, reconocimientos de sus cualidades y potenciales individuales y agradecimiento por su fuerza y lucha, y el último momento donde les deseo cosas buenas, que los sueños se realicen y los apoyo a continuaren sus luchas, personales y colectivas y que no desistan de sus sueños. Todas las cartas fueran entregues a sus destinatarias antes de nuestra salida del territorio. Cada carta tiene dibujado un pedacito del Rio Doce, y al juntar todas las cartas desvela el mapa del trayecto del lodo tóxico en la Cuenca del Río Doce. 
La poética artística como herramienta de acción política para la promoción del afecto: Una acción poético-afectiva en territorios afectados de la Cuenca del Rio Doce

Fig 8 Carta a Ana

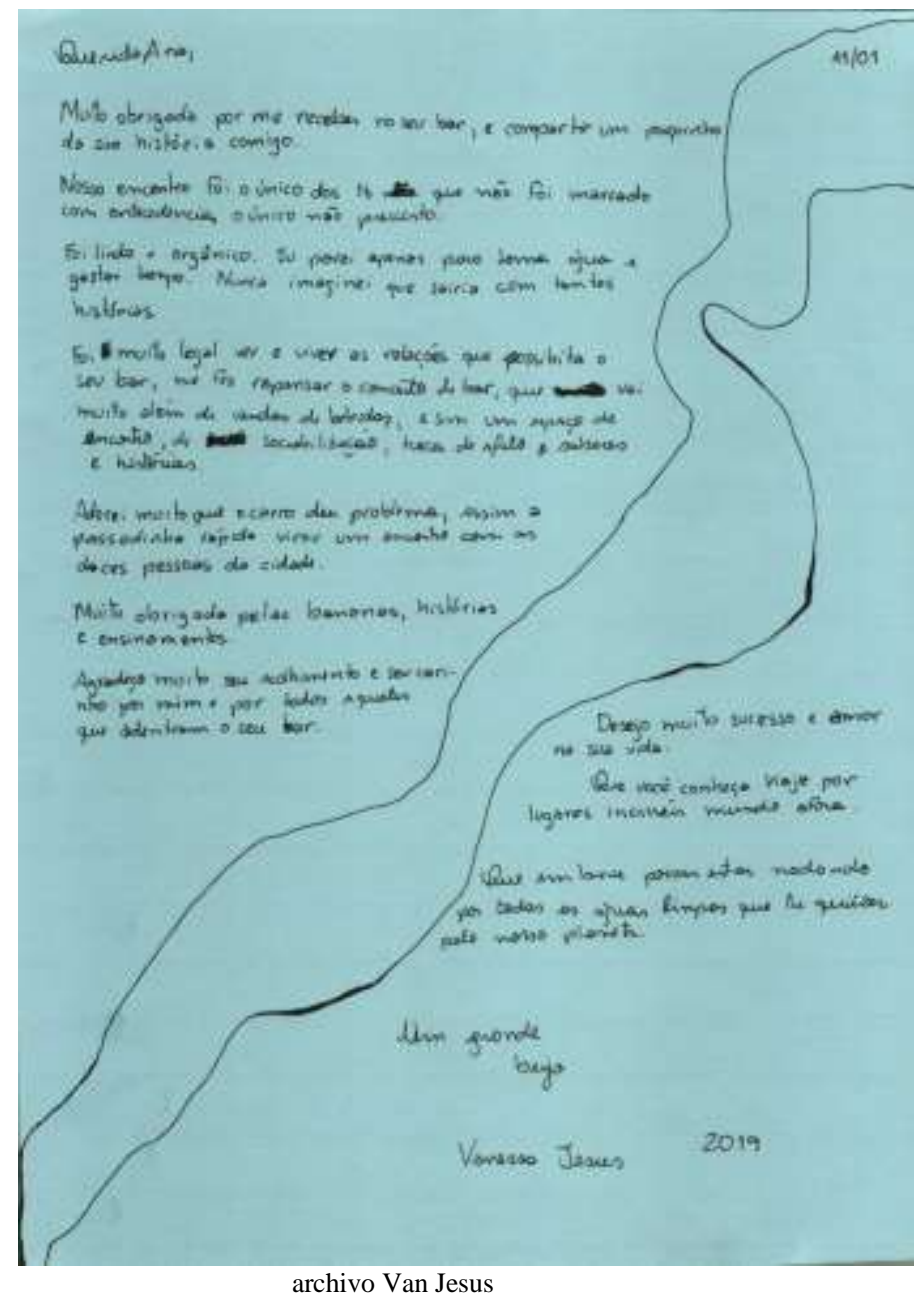

Otra parte del proyecto es divulgar sus historias más allá de las márgenes del Rio Doce. A través de la palabra en otros espacios institucionales y informales. Y también a partir de otras prácticas artísticas. A partir de testimonios de las moradoras de las tres zonas visitadas, fueran creadas dos vídeo-performances. Una en el territorio de Mariana, donde yo como performer repito el camino ancestral ya no más practicado por los nativos de la región. Una caminada de $10 \mathrm{Km}$ entre Areal y Regencia. La otra video-acción en la margen del Rio en la Ciudad de Gov. Valadares donde yo como performer devuelvo agua limpia al Rio, como una tentativa simbólica de limpiarlo y a la vez pensar sobre la cuestión de devolver los recursos como los encontramos. 
Fig 9 Videoperformance Camino Ancestral

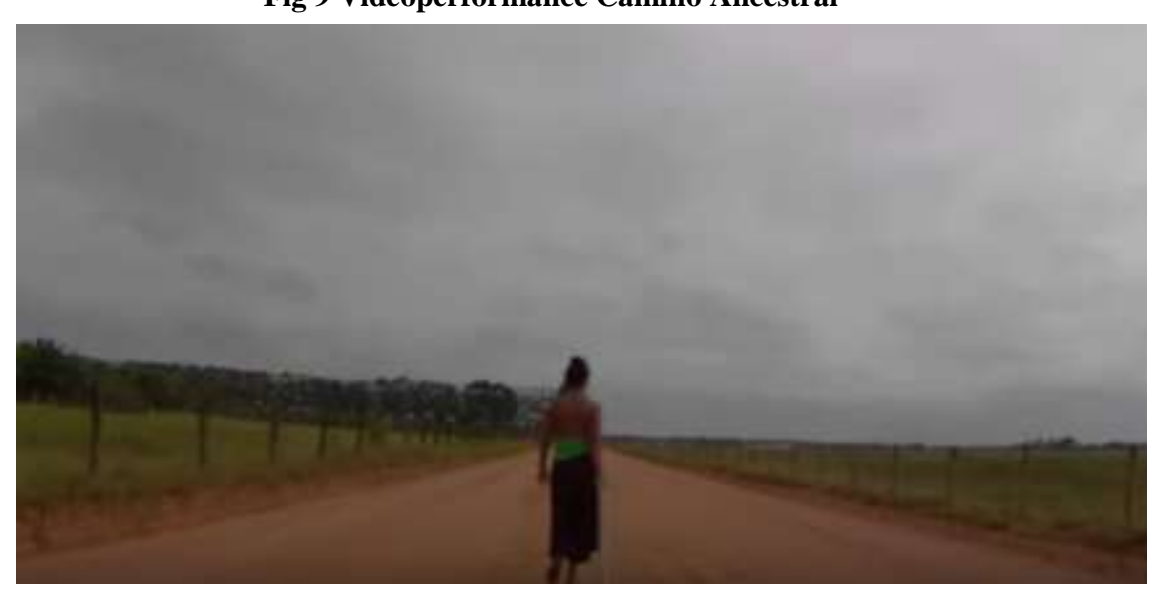

(foto: Ananda- archivo de Van Jesus)

Fig 10 Re-Ajuste

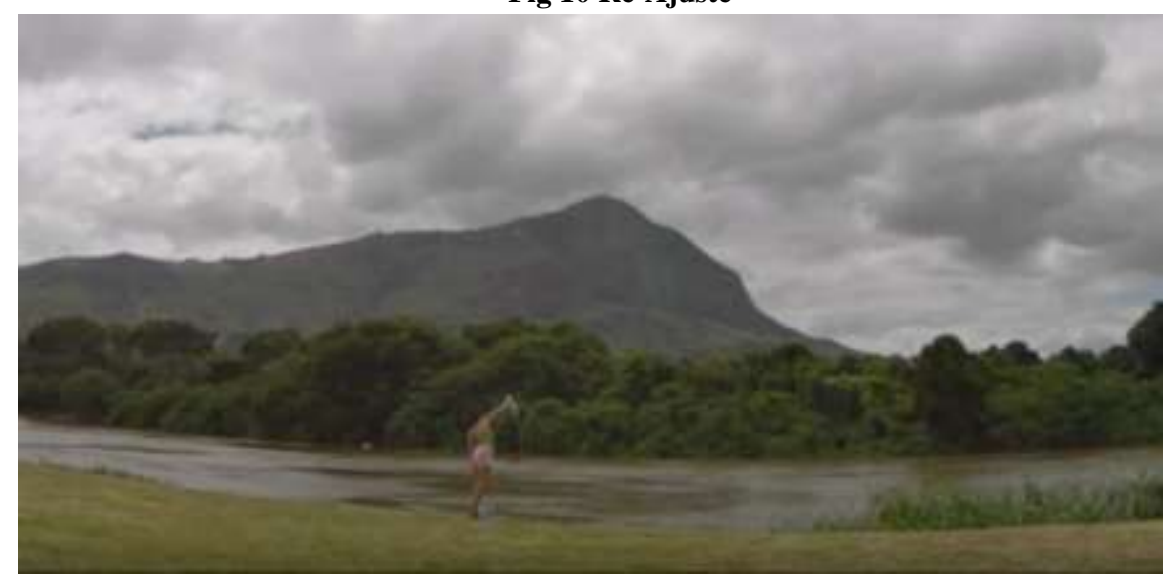

(foto: Letícia- archivo Van Jesus)

\section{Conclusiones y reflexiones}

Empezar el proyecto en el desarrollo del III Encontro Ancestral de Areal, fue esencial y fundamental. A partir del encuentro empezamos a establecer relaciones afectivas con más de quince comunidades entre las que se cuentan las comunidades tradicionales indígenas, comunidades afrodescendentes, investigadores de las universidades públicas de la zona, comerciantes, pescadores, niños, ancianos y muchos otros; todos ellos compartiendo historias, saberes, afectos, comidas y momentos entre las moradoras de los territorios afectados de toda la Cuenca.

Las conversaciones, encuentros y entrevistas con los moradores afectados proporcionaron apoyo, reconocimientos de sus necesidades, crearon vínculos afectivos y estímulos al rescate de sus sueños. En esos encuentros fueron realizadas 16 cartas afectivas a 16 moradoras elegidas de tres zonas de la cuenca. Las personas fueron elegidas por la relación afectiva que había creado con ellas y por la necesidad de apoyo y cuidado hacia a ellas. Los formatos, sus dinámicas y estéticas elegidas para ese proyecto nacerán en consecuencia de las demandas y sentidos de las moradoras, a partir de una estética propia local, de la manera como se relacionan y/o como gustarían que fuera.

La poética artística como una política del afecto, afecto a ese individuo desamparado. 
La poética artística como herramienta de acción política para la promoción del afecto: Una acción poético-afectiva en territorios afectados de la Cuenca del Rio Doce

Con la respuesta de las cartas, dos relatos de las experiencias de las artistas de Payasos sin Frontera, de la organización de la Pedagogía de la Emergencia, pude reafirmar la importancia del Arte y del Afecto en la regeneración del ser humano pos catástrofe, de cómo es posible evitar los traumas y/o amenizar sus efectos.

Pero ese proyecto es solo un comienzo de mucha acción conjunta, mucha acción poética política del afecto. Y los problemas de las comunidades ocasionados por la catástrofe están lejos de llegar al fin.

\section{Referencias}

ARDENNE, P. (2006) Un Arte Contextual: Creación artística en medio urbano, en situación, de intevención, de participación. Murcia, España: Editora Cendeac, Titulo Original: Un art contextuel.

Clowns Without Borders International. (2017) Miles of Smiles. handbook

Ruf, B. (2018) Destroços e traumas: embasamentos antroposóficos para intervençoes com a pedagogia de emergência. Sao Paulo, Brasil: Editora Antroposófica.

$\operatorname{BBC}(06 / 11 / 2015)$ "Un muerto y 16 desaparecidos por rotura de dique en mina de Brasil”. $B B C$

Mundo.Recuperado:https://www.bbc.com/mundo/noticias/2015/11/151105 25 desaparecidos accidente minerobrasil bmAces o: $7 / 09 / 2018$

$\operatorname{BBC}$ (9/05/2016) “La devastación del accidente de la represa minera en Brasil, seis meses después”. BBC Mundo.

Recuperado:https://www.bbc.com/mundo/video_fotos/2016/05/160509_video_brasil_dique_mina_lpAceso: 7/09/2018 